\title{
STUDY ABROAD, TRANSFORMATION, AND IKIGAI: A CASE STUDY
}

\author{
Olenka Bilash ${ }^{1}$ \\ University of Alberta, Canada
}

\begin{abstract}
This paper follows 10 years of evolution of a Japanese teacher of English in a small city in Hokkaido, Japan. After participating in an intensive, one-month study abroad program, Kuni and the author began regular correspondence and annual interviews that acted as a record of Kuni's professional transformation. Following case study methodology, the study reveals evidence of the impact of study abroad on Kuni's practice, while ikigai best illuminates his transformation. Satisfied with his life, able to be an agent of his own professional change, always generating and looking forward to goals and dreams, and feeling free to pursue his vision for his students appear to give him meaning and value in life.
\end{abstract}

Keywords: study abroad, teacher transformation, ikigai, TEFL

\section{Introduction}

In the year 2000, I was invited to lecture in Japan. Being multilingual and having studied abroad and worked on projects in multiple countries, it was strange for me to go to a place where I did not know the language or culture. Nevertheless, I eagerly accepted the opportunity, knowing that travel and being out of one's comfort zone is always a source of insight and fodder for personal transformation. That visit lead to annual (or more) teacher education workshops and 19 years of deep learning. My responsibility was to provide English language, culture, and pedagogy teacher education through annual seminars for teachers in Hokkaido. Selecting key aspects from my experience as a teacher educator, I did my best to teach lesson and unit planning through backward planning, scaffolding, structure, support, and student challenge, emphasizing the importance of target language use and interactive communicative activities in the classroom and the role of assessment

${ }^{1}$ Correspondence: Department of Secondary Education, Faculty of Education, University of Alberta, 347

Education South 1121087 Avenue Edmonton AB T6G 2G5 obilash@ualberta.ca 
and cando statements in planning. I also introduced task-based language teaching (TBLT), among other content. However, like thousands of teacher-educators across the Englishspeaking world, I am certain that I learned far more from working with English teachers from Asia than they learned from me. In particular, I experienced a process of discovering what I have recently learned is ikigai (Ishida, 2014; Kumano, 2017; Sone et al., 2008) or "the reason for which you wake up in the morning" (Mathews, 1996). My ikigai is teacher education, in particular, second language teacher education and, even more specifically, teacher transformation (Mezirow, 1991). I am fascinated by the hidden processes of the mind and how we bring what is deeply seeded and seated within us to life and into a sensory state that can be experienced, critiqued, and recast. My "intellectual excitement" (Bruner, 1977, p.11) in this metamorphosis has been captured by Picasso's words which I found in a museum in Barcelona: "It would be very interesting to record photographically, not the stages of a painting, but its metamorphoses. One would see perhaps by what course a mind finds its way toward the crystallization of its dream." I began to wonder these things: How do teachers find, develop, enact and crystallize their pedagogic dreams? What happens to the spark that initiates their interest in the profession and the internal forces that drive, sustain, and transform their practice? What is their raison d'etre or ikigai?

Thus, as I began to work regularly with teachers from Hokkaido, it was not surprising that I would immediately connect with the Japanese teachers who shared a strong interest in improving their own practice. Further, when one teacher, Kuni (pseudonym), chose to stay in contact with me after his one-month intensive study abroad program in Canada and continued to inquire about best practices and share experiences year after year, this too became a source of my ikigai. This paper reveals the transformation or metamorphosis I was able to record and interpret in Kuni's English language teaching practice over a 10-year period. This project has reminded me of the unwritten requirement that international teacher educators have to learn about local habitus (Bilash \& Masimira, 2015) and how long this takes. While I followed my own advice of learning a bit of the language, finding a trusting cultural broker, and asking a lot of questions (Bilash \& Masimira, 2015, p. 398) over my years in Japan, when it came to interpreting the impact of the in-service professional development program, I felt a cultural deficit. ikigai has helped me to fill this gap, although it is only one of many profound concepts embedded in Japanese language and culture. How ikigai shed light on and helped me gain insight into Japanese culture and teacher transformation may be beneficial to other international teacher educators and to all teachers seeking a deeper communion with their pedagogic selves and practice.

The paper, a case study, begins by explaining ikigai, discusses Japan's English education mandate, describes the methodology and characteristics of a case study, and presents some key themes in Kuni's evolution. It concludes with questions about international teacher education and suggestions for applications of ikigai.

\section{ikigai}

The word ikigai is usually used to indicate the source of value in one's life or the things that make one's life worthwhile. The word translated into English roughly means the "thing that you live for" or "the reason for which you wake up in the morning" (Mathews, 1996). A philosophy of finding and establishing meaning in life (Ishida, 2014), ikigai is associated with a variety of favorable outcomes (Solomon, Berg, \& Martin, 2011; Tanno et al., 2009) and develops from positive intrinsic rewards such as being moved or inspired by other people and events, experiencing success with challenging tasks, engaging in empathetic conversations with others, spending time and playing in beautiful 
natural surroundings (Ishida \& Okada, 2006, 2011), and establishing warm-hearted human relations (Ishida, 2014). ${ }^{2}$

Mieko Kamiya (1966/1980, 2004), as reported in Kono (2017, pp. 22-26), was one of the first researchers to extensively study and theorize ikigai. Based upon her observations as a psychiatrist at an internment camp for leprosy patients as well as a review of studies that examined people suffering from other transitional life events such as bereavement and the dropping of atomic bombs, she distinguished between perceptions and sources of ikigai. She asserted that perceiving ikigai or purpose required an individual to have satisfied seven types of personal needs. These include (a) the need for life satisfaction, (b) the need to be able to experience change, (c) the need to hold belief in a bright future (mirai-ser), (d) the need to feel like what one is doing resonates in one's surroundings (hankyo), (e) the need for freedom, (f) the need for self-actualization, and ( $\mathrm{g}$ ) the need for feeling meaning and having value in life. According to Kamiya (2004), the need for life satisfaction was "the most basic" (p. 54). Kono (2017) reports that Kamiya (2004) also identified six common characteristics of sources of ikigai. A source of ikigai: 1) provides one with ikigai perception; 2) does not necessarily have instrumental value; 3 ) is autonomous or intrinsically motivated (e.g. leisure or what you do in your free time); 4) is unique to each individual, consistent with his/her identity and is an outlet for true self-expression; 5) helps construct a value system in one's mind; and 6) contributes to creating an internal mental world in which one can live freely. The distinction between the perception of ikigai and its sources has had a strong conceptual influence on later ikigai researchers (e.g., Hasegawa et al., 2003; Kumano, 2017).

Other researchers have concurred with and clarified these characteristics. Sociologist Shyunta Mori (2001), as reported in Kono (2017, pp. 36-7), views ikigai as constructed through everyday lived social interactions and identifies self-affirmation or the freedom to be oneself as the core part of ikigai. He further theorizes that three dimensions of ikigai make this possible: (a) social networking or the quantity and quality of one's interpersonal relationships across various life domains including family, work, friends, and community; (b) life course or one's "vertical" connections (or tate-no-tsunagari) or one's temporal relationship with self across the past, present, and future; and (c) life values and worldviews and acting upon them. Higher levels of ikigai are perceived when social networking is abundant, there is a high level of consistency in one's relationship with one's self across time, and one's views and values are clear and acted upon.

Building on the work of her predecessors, Kumano (2006, 2013, 2017) developed an ikigai awareness scale with five dimensions: (a) life affirmation, (b) goal and dream, (c) meaning in life, (d) existential value, and (e) commitment (Kumano, 2006). She also argues that igikai awareness is most frequently associated with actions, especially doing things one enjoys and devoting oneself to the endeavour; is future and long-term oriented; includes a

\footnotetext{
2 When I decided to use ikigai as a theoretical interpretive lens, I contacted some of the teachers who participated in the study as well as the supervisors who had validated the findings. None had ever discussed ikigai in educational contexts, neither in their undergraduate years nor in their professional development (including the compulsory five-, ten-, and fifteen- years of teaching experience seminars). Although Matthews (2006) explores ikigai with university-level students, his work was criticized for not relating more to education (Mouer, 1997), but also frequently referred to in studies in higher education institutions. In a nonevidence-based study Eller (2016) has gone on to hypothetically point out the connections between ikigai and education. However, to date, no studies have connected ikigai and public school teachers in Japan or elsewhere. As a disclaimer, I also note that the few authors who venture into the territory of ikigai and education are nonJapanese.
} 
sense of worthiness, zest, meaning and purpose, and existential significance; and entails the active effortful pursuit of something difficult for the benefit of others.

\section{Teaching English in Japan}

In Japan, the study of English is mandatory in Grades 5-9, at the high school and university levels and, for most Japanese students, it is not only the primary second language of study but also a focus of high-stakes examinations for entry into junior and senior high schools and also universities - and eventually facilitating well-paid employment and workplace mobility. With the establishment of the National Council for Educational Reform in 1984, the struggle to reform English education in Japan and shift the emphasis from reading and grammar to the development of communicative skills has been high on the national agenda. Through a series of ongoing policy guidelines, the Monbukagakusho or the Ministry of Education, Culture, Science, and Technology (MEXT) has repeatedly attempted to reform English language teaching methods over the past decades by:

- introducing a "period of integrated studies" with English language activities starting from Grade 3 in elementary schools;

- highlighting the importance of developing communicative abilities;

- increasing the number of English language classes at high schools;

- introducing new textbooks with more activities for developing communication skills;

- introducing training courses for teachers so that they can become proficient in communicative language teaching;

- encouraging teachers to use more English for instruction and to help their students develop communication skills;

- reevaluating the role of assistant language teachers (ALT) and better integrating them into the system; and finally,

- revising the entrance examination of secondary schools and universities (Monbukagakusho, 2001)

More recently, MEXT has made the teaching of English a compulsory graded subject beginning in Grade 5 and doubled the vocabulary content in each grade, thus aiming to have high school students ready for post-secondary content study abroad (Monbukagakusho, 2016).

MEXT directs and monitors all educational endeavours in Japan. From developing curricular targets in all subject areas to approving all textbooks and through the Japanese hierarchy ensuring a tight correlation between textbook content and final examinations, to identifying new directions and pilot projects and dispersing funds for professional development, MEXT heavily influences teachers' pedagogical understandings and practices. Routines of practice are established around these constraints, and each section of a lesson and school day is tightly scheduled and timed literally to the minute. It is rare for teachers not to follow proposed and established practices, unless they are participating in an 
innovative pilot project. In this case, MEXT carefully monitors the activities and student outcomes with the goal of establishing dependable and time-appropriate structures for others to follow when the pilot project is completed, and its results shared. Kuni's willingness to stretch these limits, outside of a formal pilot project, make his interviews further worthy of attention in this research endeavour.

\section{The Case Study}

This paper is a case study focusing on Kuni and his transformation. A qualitative case study investigates a real-life, contemporary bounded system (a case) over time, through detailed, in-depth data collection (Creswell, 2013). The case study's unique strength is the variety of evidence sources that can be considered including documents, artifacts, interviews, recordings, and observations (Yin, 2009). The case study strategy has a distinct advantage over other research approaches when a 'how?' or 'why?' question is being investigated about a contemporary event over which the investigator has little or no control. Qualitative researchers seek to understand a case- to appreciate the uniqueness and complexity of it, its embeddedness and interaction with its contexts (Stake, 1995, p. 16). Kuni's commitment to resolving his inner concerns about teaching English over adhering to professional conformity is what makes Kuni's case particularly unique.

The case study is ideal for my investigation as it: 1) allows me to explore what makes Kuni act upon what he has learned; 2 ) enables me to analyze the multitude of data I have acquired in oral and written dialogue with Kuni over a ten year period; 3) offers me an opportunity to observe and share observations about practice in classes where I could never be on a daily or even seasonal basis; 4) offers me insights into the thinking of teachers (from another cultural habitus) with whom I work as an in-service teacher educator; and 5) offers an opportunity to share the story of an influential though 'unofficial' teacher educator.

\section{Data Collection}

Kuni and I met when he was a member of a cohort of English teachers who came from across Hokkaido to the University of Alberta for the Hokkaido Teachers of English program (HTEP), a one-month intensive language, culture, and pedagogy study abroad program. To protect his identity, I am unable to state the year in which he participated as only about a dozen teachers came to Alberta each year and only 50 per cent were male. His group of teachers, along with the cohorts before and after, all participated in a larger study that entailed observing and video-recording them teaching in their classrooms and holding 40-80 minute interviews with them. The data from the 78 interviews were triangulated with the video recordings and the teachers' lesson plans to create five scenarios that described their thinking and planning practices. The scenarios were then validated by hundreds of teachers in seminars and eight supervisors whose responsibilities include observing teachers and lessons across Hokkaido.

The data reveals a variety of responses to the impact of the study abroad experience from the 78 teachers. Despite having time to write daily reflections and engage in group dialogue directed by a Japanese supervisor, the writing and observation sessions of some teachers revealed minimal conceptual change. They resisted using English in their classrooms, they structured lessons according to the textbook, and they continued to perceive their teaching responsibilities as helping students pass the high-stakes exams. While some teachers increased their use of English in the classroom and shifted to more communicative practices, fewer seemed to seek ways for students to "experience English" as a language of communication and a tool for learning in Japan. 
Among all the participants, those members of scenario 5 were most intriguing to me They all deeply valued the HTEP study-abroad experience, formed bonds with members of their cohort and members of previous and later cohorts, and took initiative to share their insights with their local peers. None spoke of systemic barriers preventing them from pursuing their own goals; rather they overcame them. But even among this group, Kuni was still an outlier.

The data presented here are drawn from a much larger longitudinal action research (AR) study ${ }^{3}$. AR traces the growth, changes, and challenges faced by individuals and institutions and their responses in daily lived experience. In AR, it is common for the researcher to be an active team member-in this case the director and chief instructor of HTEP_-working alongside decision-makers to adapt HTEP to local needs from year to year. Action research typically explores and addresses issues in cycles that consist of four steps of planning, acting, observing, and reflecting. Cycles are not always clearly delineated, and often several issues or explorations run parallel and simultaneously through a single cycle. All of those involved in HTEP in Canada and Japan tried "out ideas in practice as a means of improvement and as a means of increasing knowledge about the curriculum, teaching, and learning" (Kemmis \& McTaggert, 1982, p. 5). We were particularly interested in exploring changes in teacher practice.

Over the years I met and interviewed Kuni over ten times for the study. His initial lesson plan, recorded lesson, and post-teaching interview were supplemented with recorded conversations ${ }^{4}$, additional classroom observations and discussions thereafter, and our correspondence which also included video links and lesson plan and handout attachments. All these data were analyzed and thematically coded. Constant comparison analysis coding took place manually in three steps (Strauss \& Corbin, 1998). First, I, the coder, listened to 20 hours of recordings, made summary transcripts, and read these and other written texts multiple times to get a sense of the flow of our discussions over the years. Then I chunked the 70 pages of data into small units. During the second axial coding stage, I grouped the small chunked units into thematic categories (Onwuegbuzie, Dickenson, Leech \& Zoran, 2009, p. 6). Stake (1995) purports that in case study analysis the most important meanings come from recurring appearances. In the third and final selective coding stage, I developed the themes reported here. Since all the citations are from Kuni, I have only indicated the year after each one.

\section{Findings}

We now examine the themes from Kuni's responses, noting how they shed light on his ikigai and postulate its important role in teacher agency and transformation. The coded themes that emerged from the ten years of Kuni's transcripts are love of teaching, selfinitiative, working with ALTs and vision for students.

\footnotetext{
${ }^{3} \mathrm{AR}$ aims to record events and discussions in a systematic manner but does not typically set up hypotheses or work in a linear manner. Minutes from meetings, daily reflections of almost one thousand teachers, conversations with senior advisors, correspondence, annual reports, annual feedback from teachers and recorded lessons, observation notes and interviews with teachers about school visits have been consulted in this larger longitudinal study.

${ }^{4}$ Our face-to-face conversations were sometimes rhizomatic meanderings; we covered many topics with multiple, non-hierarchical entry and exit points. We each took the lead on changing direction, returning to something exchanged minutes or years earlier and sharing what was on our mind at the time. We listened with raw openness (Anzaldua \& Keating, 2013), perhaps seeing in the other a committed, trusting (McClellan \& Sader, 2012) and caring (Noddings, 1984) listener. ... and not a deviant (hooks, 1989).
} 


\section{Love of Teaching}

Kuni loves the classroom. His "interactions with students are meaningful" (2012, 2013, 2014, 2015); yet, as a respected English teacher in his geographical area, he is also expected to move into a position of moral and administrative leadership-especially as he approached 45 years of age. In general, in Japan, teachers cannot become principals until they reach 50 years of age and do so only after passing a series of intensive written exams, an oral interview, and experiencing many years of other forms of administrative support such as being a vice-principal or a supervisor for a school district. Kuni was "told many times that [he] cannot be a teacher forever" (2015), a subtle Japanese signal that he should be preparing to enter an administrative post.

Despite these indications, he had continued to resist leaving the classroom and following the expected path of educational leaders. In transcripts from our annual discussions and correspondence, Kuni never failed to have new teaching goals, and each year they were more precise and more specific. In 2012 he said:

I must develop activities or tasks that make students WANT to communicate in English So I think of ways for review of what we have taught recently while recycling what students learned a long time ago and must remember. Students need to keep practicing this or they will forget it, but they need tasks that will challenge their thinking and challenge them to use English.

In 2013 he reported: "I am still learning to give more support during scaffolding (small steps)" (2013). In 2014, he recognized that "preparation time is most important now. I prepare materials for each small step (scaffolding) so that students can succeed. I enjoy creating the activities and tasks that spark student interest” (2014). Kuni exudes ikigai awareness as he describes doing things he enjoys, even though they are difficult and time consuming, maintaining a future and long-term orientation, and devoting himself to developing resources for the benefit of others (Kumano, 2006). In January 2015, Kuni wrote:

In classes during THIS school year, I have applied things I learned through your seminars and HTEP more than before. Especially I liked the poster activities that you introduced us in September. After the seminar I ask my students to make posters to use expressions that they learn from the textbook. Nowadays, they can work together well and can finish making them in TEN minutes. So, it means more output will be able to happen in class!"

It seems quite a feat for Kuni to have not only achieved a path to increasing student output in class but also within a timeframe that Japanese teachers would consider adoptable and realistic.

In September 2016, Kuni wrote to me about a cooking class he had planned with his students: "I had a wonderful time in August. ALTs in [my area] gave me a big help, so that I could finally realise one of my dreams - to have students experience and enjoy learning through English.” 
Over these years, Kuni's actions and words reveal a love of teaching English, a longterm devotion to his students and profession, and a constant generation and realization of personal goals and dreams for his students-all characteristics of ikigai. Moreover, examining Kuni's thinking about his practice suggests that Ishida's (2014) definition of ikigai as a philosophy of finding and establishing meaning in life might be extended to education.

\section{Initiative}

Kuni undertook his own professional development program, pursuing a burning query for over a decade. Early in his career, he "knew that there was something in [his] teaching that needed to change, but [he] couldn't figure out what" (2013). Reflecting on lesson planning, participating in lesson study (Fernandez, 2002; Fernandez et al., 2003), sharing with colleagues, and examining the textbook were all sources of his ikigai.

In 2012 he described how his planning and preparation for teaching changed:

Twelve years ago (in my fifth year of teaching) my school had a very difficult time. I did not have enough time to prepare. I had no plan at all. I just went to class with my textbook and said 'open the textbook' and I taught".

"I was frustrated, and for many years... Then....hmm I wanted to change. In my first year as a teacher I attended a lot of seminars and I learned a lot about English teaching, but I did not have time to prepare at that time. Then my preparation changed. I created lesson plans based on what I had learned in the in-service seminars. After that the students became better year by year."

Kuni's ability to articulate his transtemporal relationship reveals a high level of consistency in his relationship with himself over time, a characteristic of ikigai posited by Mori (2001).

He also shared his own process of working through issues relating to teaching. In addition to "a lot of self-study", Kuni "got good chances," adding, "for example I studied for three weeks in A., went to HTEP in Canada and your seminars in Japan. Then my frustrations got smaller and smaller" (2012). Here Kuni sees that study abroad offers not only an opportunity to leave his familiar milieu but also the time that such programs provide for reflection on his practice. The powerful role of reflection in teacher transformation is now well documented the world over.

Kuni appreciated B-SLIM (Bilash, n.d.) as it offered him an "x-ray of the structure of lessons" (2011): "I went to a lot of demonstration lessons all over Japan. What did they have in common? They were structured according to B-SLIM ${ }^{5}$ only no-one ever talked about it or taught us how to do it. Now I read a lot on my own about second language acquisition (SLA)" (2012).

Making concrete connections between the content learned in study abroad and his classroom were milestones for Kuni:

\footnotetext{
${ }^{5}$ Bilash outline details of B-SLIM in her website, Best of Bilash: Improving Second Language Education, at https://sites.educ.ualberta.ca/staff/olenka.bilash/Best\%20of\%20Bilash/home1.html.
} 
When I took HTEP I was able to understand scaffolding - after I got to know B-SLIM I understood what I had learned at university and more things became clearer. It was very simple: start with input and end with output. So, my lessons start with input and end with output” (2012).

Kuni shared the connections he was making with his colleagues: "I have shared BSLIM with many other teachers and they now understand more about their teaching and make better lessons. Many are now on maternity leave, so we have not had so much time to work together for a while" (2013). Kuni's self-challenge brought him intrinsic satisfaction and affirmation as he was able to reveal his success through demonstration classes and explain their skeletal structure to his peers.

Reflections on the "x-rays of lessons" lead Kuni to reconceptualize the role of the textbook in his teaching: "The textbook is a good guide. It gives me direction about grammar, themes or topics and provides some good reading materials. The workbook is also useful. But it does not offer real opportunities for communication” (2012).

Two years later, he reported a change in his understanding of the textbook: "I now see what the textbook does not offer and so I teach in a new way." (2014) "I presented a demonstration for teachers in [area] this week. They saw [my] students speaking in English and enjoying English.” (2015). The freedom he allowed himself to explore, experiment with, and change his practice became self-affirming as others sought his advice.

An activity that fosters ikigai is autonomous or intrinsically motivated. Kuni's positive spirit, feeling of agency and autonomy (freedom), and ability to consistently reach out to help others are all sources of ikigai (Kamiya, 2004).

\section{Equality with the $A L T$}

Kuni's relationship with Lenny, his foreign assistant language teacher (ALT) was the most unique among the 78 participants in the larger study:

Three years ago, I was thinking about the ALT and how to share our responsibility in the classroom. Recently I recognized that we were not sharing responsibilities with the ALT. I explained to Lenny and he said that the best word to describe this was ownership. We share ownership in the classroom. As you said, the teacher and the ALT working as a team means two mouths, four eyes, four hands, four legs, two hearts ....all to help students" (2012).

Although Japan has invested billions of dollars in the Japan Exchange and Teaching Programme (JET)/ALT program since it began in the 1980s, many teachers do not know how to utilize these foreign native speakers of English to maximize the development of their students (Amaki, 2008; Carley, 2013; Ohtani, 2010). The majority of the study abroad participants responded that the ALTs were an important model of pronunciation and often provided new games or activities to motivate their students. Kuni's comments, however, were different:

I don't like to use the ALT as a human CD player. I want to respect my ALTs because they have lots of experiences from another country and I also wanted to be respected. So I wanted time to give my students a chance to get 
to know Lenny as who he is. Actually, I wanted him to stand not in front of me or behind me but beside me (2010).

Kuni sees Lenny as a peer- he does not situate him in the Japanese hierarchy of relationships: "We have many things in common - age, parents of two children. So we think of each other as friends, co-workers, colleagues in the same space" (2012).

Kuni values Lenny: "I do a lot of self-study and discuss many ideas with my ALT" (2012). "Some teachers say that they have no time to work with the ALT, but at the same time this means that they do not show respect to the ALT" (2012). Kuni and Lenny seem to enjoy what Zwart et al. (2007) see as an effective non-hierarchical peer coaching relationship.

ikigai evolves in everyday living during which one can be oneself (Mori, 2001) and flourishes with quality interpersonal relationships that stretch across various life domains; Kuni clearly saw Lenny as a friend, colleague, and community member.

\section{Vision for Teaching}

When asked about his vision for teaching junior high English students, Kuni responded in these ways:

Hmmm....hmmm. I think I want my students to be more aware of the world because some of my former students haven't found their job yet after graduating from university... and some are complaining about their lives and social problems. But if they can speak English or other foreign languages I think that it makes something easier in their life (2012).

In my experience, visiting other countries is something special. If I were younger, like twenty-something, I would like to live in other countries. When I was twenty-something Japan was very closed and it is still closedit is very hard for foreign workers to work in Japan. I want to help open up Japan in my students' minds (2013).

I want my students to feel like they can use English in Japan (2014).

During the period of 2012 through 2014, Kuni's interviews capture his belief in a bright future (mirai-sel) and in feeling as if what he is doing resonates in his context (hankyo). Trying to change Japan's closed-minded attitudes toward foreigners through his students gives him meaning and purpose (Kamiya, 2004).

To further make English come alive for his students, Kuni heavily invested in his discussions with Lenny, and as Lenny became fluent in Japanese he was more able to identify factors in his own second language acquisition (SLA) that could apply to their students. After discussions with Lenny in 2011, Kuni created 'Lenny money' so that youth in his community would be able to use English outside of school. Lenny money featured a photo of Lenny on the pseudo paper currency, and Lenny was given ample "cash" to carry with him for distribution whenever students spoke with him (in English) outside of the school. Kuni's vision was to have students see English as a means of communication that could be used in Japan. He encouraged students to talk to Lenny anywhere they saw himat the mall, on the street, or at a local festival. In turn, Lenny would give them some Lenny money which they would then present to Kuni. Intrinsic rewards are a primary 
characteristic of ikigai, and there were no prizes for earning Lenny money-- nor any sense of competition. Having the courage to talk with Lenny and then tell Kuni about it was the intrinsic reward.

With their readings, discussions, experimentation, and collective reflection, Kuni and Lenny had created a professional learning community (PLC) (Dufour, 2004), a wellproven strategy to support effective teacher professional development and change (Dufour, Dufour, \& Eaker, 2008). However, whereas the PLC movement is driven by top-down policy implementation (Coburn \& Stein, 2006), ikigai is intrinsic. One cannot give another ikigai nor define it for them. ikigaicannot become a tool co-opted by reformers and subjected to scales of excellence. Rather, it is a non-egocentric state in which individuals balance their personal life satisfaction with accomplishments of the common good; one perceives ikigai through validation from others or the wider society, such as professional peers (Wada, 2006).

\section{Summary}

Already strong in English, Kuni stood out as an exceptionally eager learner of second language pedagogy. He became the focus of this paper because he demonstrated strong self-direction. Moreover, we were able to meet annually for 60-120 minutes over a 10-year period and exchanged many emails throughout the year, thus offering me an opportunity to record his transformation over time. Navigating a system that constrains certain types of development due to the three-year teacher transfer policy, Kuni managed to stay in his school seven consecutive years. This enabled him to enact some of his new ideas and establish a different English language teaching habitus (Bourdieu, 1977) among students, teachers, ALTs, and administration. Indeed, he is an agent of change in his school and geographical area. As an outlier who is uninterested in advancing to power in an administrative position, Kuni reveals how personal agency and his ensuing pedagogic transformation can take place when fuelled by ikigai.

While there is evidence of the impact of study abroad on Kuni's practice, it is ikigai that best illuminates his influence and transformation. Satisfied with his life, able to be an agent of his own professional change, always generating and looking forward to goals and dreams, and feeling free to pursue his vision for his students seem to give him meaning and value in life. Kuni's broad social network with multiple ALTs, other teachers, students and their parents, and his administration also gave him a stable daily foundation for further selfactualization.

Teaching English is a source of Kuni's ikigai; therefore, it is no wonder that he resists the normative expectations of his age and accomplishments. Just before this article was submitted, I received correspondence from Kuni indicating that he has now become a senior teacher providing assistance to the Vice Principal in a large school. He reports: "teaching only one class of English. Sad" (2019). Despite his accomplishments, he may not be able to resist greater conformity much longer. I wonder how this will influence his ikigai?

\section{Limitations}

Although this study offers a unique insight into the impact of study abroad on the experiences of one Japanese teacher of English, the use of ikigai is limited by this one case. Further, Kuni expressed himself in English which, while strong, is his second language, and he may not have been able to provide all the details and nuances that he wished. Third, since a case study aims at particularization, generalizations should not be made to other 
teachers or areas in Japan. Finally, the use of ikigai as a lens is a choice made by the author and not by Kuni or other educators in Japan; it is possible that the author lacks sufficient cross cultural understanding to present ikigai.

\section{Discussion and Implications}

Kuni's case study offers insights for both teacher-educators and researchers. Although he himself never used the term ikigai, his evolution as a teacher and the transformation of his teaching practices reveal perceptions and sources of ikigai. Reflecting on this study, I offer the following forward-looking queries.

1. Given the evidence of ikigai in the life of one influential teacher, might it be possible for the existing research on ikigai among university students and the elderly in social work, sports, and medicine to be extended to all teachers in Japan? Might a discussion of ikigai spark reflection during teachers' education programs and compulsory five, ten, and fifteen year in-service training sessions in Japan? For example, questions along the lines of the following might generate fruitful discussion: What brings you satisfaction (in life)? What do you sense is your own purpose in life? What would you like to change in the world, and how are you acting to bring this change about? Regarding the previous question: How does this desired change relate to teaching in general and to your teaching specifically?

2. Kuni describes "learning a lot" (2012) during his teacher education program, professional development seminars, early teaching demonstration lessons, and study abroad experiences. However, he also emphasized that he did not have "enough time to prepare" or apply what he learned. In fact, he only made a conscious concerted effort to do so more than a decade after he began his practice. This scenario underscores similar issues of teachers lacking time to "teach". As studies in Australia (McGrath-Champ, Wilson, Stacey, \& Fitzgerald, 2018) and Canada (Alberta's Commission on Learning, 2003; Dibbon, 2004; Froese-Germain, 2014; People for Education, 2019) have shown, teachers are often overloaded with tasks that siphon their energies and attention away from actual teaching. Such teachers experience pressures from the steady demand for more data and record keeping; from delivering increasingly more accurate tracking, measurements, recording, and reporting on student achievement; and from practices that emerge from documents, ratings, and policies that act as the driving forces for improvement. Under these sorts of pressures, where can teachers find the time to become aware of their ikigai? Similarly, how can school systems prioritize the creation of both time and space for teacher reflection?

3. Through Kuni's experiences, it is clear that it takes time for practice to evolve. With schools and administrators identifying new priorities every year, what measures are they taking to provide teachers time to experiment, revise, succeed, and share practices of interest to them?

4. In an extensive study of 160 teachers in Switzerland, Huberman, Grounauer, and Marti (1993) document the trajectories of secondary teachers' lives and characteristics during each of five phases of their development. The researchers conducted individual interviews and noted differences between those who passed through a phase in a positive manner and those who struggled due to professional 
and/or personal challenges in their lives. Many of the struggling teachers became disillusioned with education, especially if they did not readily accept the changes proposed and demanded by administrators and policy makers. Might they experience more fulfilling careers through awareness of ikigai and the freedom to integrate and act as free agents upon their passions within their practice?

5. Despite attendance at professional development events, Kuni was unable to immediately apply his discoveries and learnings in his own classroom. In fact, only when he reached a point of intense "frustration" did he make such actions a priority in his professional life. One must ponder whether or not this level of frustration is indeed a necessary precondition for transformation. If so, what are the consequences? If other ways could be found to achieve the same thing, would it not be in the interests of all parties to mobilize them?

As international teacher educators, we most frequently convey Western ideas and concepts to our audience. Could we merge these ideas with local "cultural" wisdom to increase potential for self-initiated teacher change? Just as ikigai is deeply rooted in Japanese thinking, so are other concepts of equal foundational importance in diverse international settings - for example, Ubuntu in Africa. In our increasingly global and complex educational milieu, we need to draw from all wisdom sources to inspire and empower teachers to be agents of their own change. As teacher educators and researchers, how can we integrate both outside and local ways of knowing into our own practices in foreign or nonlocal sites and bring them home to enrich our own understandings and contexts for the good of all?

\section{References}

Alberta 's Commission on Learning. (2003). Every child learns, every child succeeds: report and recommendations. Edmonton, AB: Author.

Amaki, Y. (2008). Perspectives on English education in the Japanese public school system: The views of foreign assistant language teachers (ALTs). Educational Studies in Japan: International Yearbook, 3, 58-62.

Anzaldúa, G., \& Keating, A. (2013). This bridge we call home: Radical visions for transformation. New York: Routledge.

Bilash, O. (n.d.). Retrieved from https://sites.educ.ualberta.ca/staff/olenka.bilash/Best\%20of\%20Bilash/home1.html.

Bilash, O., \& Masimira, M. (2015). Searching for the place of habitus in the academy. In R. Evans, L. Formenti, L. West, \& N. Verlag (Eds.), Before, beside and after (beyond) the biographical narrative (pp. 397-407). Duisberg: Nisaba Verlag.

Bourdieu, P. (1977). Outline of a theory of practice. Cambridge: Cambridge University Press.

Bruner, J. (1977). The process of education. Cambridge, MA: Harvard University Press.

Carley III, H. F. (2013). Team teaching styles utilized in Japan: Do they really work? Journal of International Education Research, 9 (3), 247-252. Retrieved from https://doi.org/10.19030/jier.v9i3.7882

Coburn, C., \& Stein, M. (2006). Communities of practice theory and the role of teachers' professional community in policy implementation. In M. Honig (Ed.), New directions in education policy implementation: Confronting complexity (pp. 65-82). Albany, NY: SUNY Press. 
Creswell, J.W. (2013). Qualitative inquiry \& research design: Choosing among five approaches. Thousand Oaks, CA: Sage.

Dibbon, D. (2004). It's about time. Newfoundland Teachers Association.

DuFour, R. (2004). What is a "professional learning community"? Three big ideas guide this school reform effort: Commitment to student learning, a culture of collaboration, and a focus on results. Educational Leadership, 61(8), 6-11.

DuFour, R., DuFour, R. B., \& Eaker, R. E. (2008). Revisiting professional learning communities at work: New insights for improving schools. Bloomington, IN: Solution Tree.

Eller, R. (2016). Ikigai and higher education: A review of the literature. Assumption University-eJournal of Interdisciplinary Research, 1(2), 50-54.

Fernandez, C. (2002). Learning from Japanese approaches to professional development: the case of lesson study. Journal of Teacher Education, 53(5), 393-405. doi: $10.1177 / 002248702237394$

Fernandez, C., Chokshi, S., Cannon, J., \& Yoshida, M. (2003). Learning about lesson study in the United States. In M. Beauchamp (Ed.), New and old voices on Japanese education. Armonk, NY: M. E. Sharpe.

Froese-Germain, B. (2014). Work-life balance and the Canadian teaching profession. Ottawa: Canadian Teachers Federation.

Hasegawa A., Hujiwara Y., Hoshi T., \& Shinkai S. (2003). Regional differences in ikigai (reason (s) for living) in elderly people-Relationship between ikigai and family structure, physiological situation and functional capacity. Nihon Rounen-igaku Zasshi, 40, 390-396.

hooks, b. (1989) Talking back: Thinking feminist, thinking black. Brooklyn: South End Press. Huberman, A. M., Grounauer, M., and Marti, J. (1993). The lives of teachers. London: Cassell. Ishida, R. (2014). Does traditional Japanese culture help people cope with stress using the concept of ikigai (reason for being)? British Journal of Education, Society \& Behavioural Science, 4, 1592-1600. doi:10.9734/BJESBS/2014/4189

Ishida, R., \& Okada, M. (2006). Effects of a firm purpose in life on anxiety and sympathetic nervous activity caused by emotional stress: Assessment by psycho-physiological method. Stress and Health, 22(4), 275-281.

Ishida, R., \& Okada, M. (2011). Factors influencing the development of "purpose in life" and its relationship to coping with mental stress. Psychology, 2(1), 29-34.

Kamiya, M. (1966/1980). ikigai ni tsuite [On ikigą]. Tokyo, Japan: Misuzu Shyobou.

Kamiya, M. (2004). ikigai ni tsuite: Kamiya Mieko korekushyon [On ikigai: A collection from Mieko Kamiya]. Tokyo, Japan: Misuzu Shyobou.

Kemmis, S., \& McTaggart, R. (1982). The action research planner. Victoria, Australia: Deakin University Press.

Kono, S. (2017). Theorizing linkages between ikigai (life worthiness) and leisure among Japanese university students: A mixed methods approach. (Doctoral dissertation) Edmonton, AB: University of Alberta. Retrieved from https://era.library.ualberta.ca/items/f75f1af3-d777-4e63-a84acf726e7ee4bo/view/44028292-41 e4-4bcf-ba69Oa7bfe552fcc/Shintaro_Kono_201712_PhD.pdf

Kumano, M. (2006). Ikigai to sono ruiji-gainen no kouzou [A structure of ikigai and related concepts ]. The Japanese Journal of Health Psychology, 19(1), 56-66.

Kumano, M. (2013). Ikigai keisei moderu no sokutei shyakudo no sakusei: Ikigai purosesu shyakodu to ikigai iyoutai shyakudo [Construction of scales for the ikigai 
development model: The scales for ikigai processes and ikigai states]. The Bulletin of Education, 39, 1-11.

Kumano, M. (2017). On the concept of well-being in Japan: Feeling shiawase as hedonic well-being and feeling ikigai as eudaimonic well-being. Applied Research in Quality of Life.13, 2-3. doi: 10.1007/s 1 1482-017-9532-9

Mathews, G. (1996). What makes life worth living?: How Japanese and Americans make sense of their worlds. Berkeley, CA: University of California Press.

McClellan, P., \& Sader, J. (2012). Power and privilege. In J. Norris, R. Sawyer, \& D. Lund (Eds.), Duoethnography. Dialogic methods for social, health, and educational research (pp. 137-156). Walnut Creek, CA: Left Coast Press.

McGrath-Champ, S., Wilson, R., Stacey, M., and Fitzgerald, S. (2018). Understanding work in schools: The Foundations of teaching and learning - 2018 Report to the NSW Teachers Federation. Perth: Curtin University of Technology, School of Management.

Mezirow, J. (1991). Transformative dimensions of adult learning. San Francisco: Jossey-Bass. Monbukagakusho (Ministry of Education, Culture, Sports, Science and Technology (MEXT). Retrieved May 20, 2008, from http://www.mext. go.jp/b_menu/shingi/chukyo/chukyo3/siryo/004/06040519/002/002.htm Monbukagakusho (Ministry of Education, Culture, Sports, Science and Technology (MEXT). (2016) Heisei 27-Nendo “"Eigo Kyoiku Jisshi $\mathrm{J}^{-}$oky ${ }^{-}$o $\mathrm{Ch}^{-}{ }^{-}$osa' no Kekka ni Tsuite" [On the Results of "Survey on the Implementation ${ }^{-}$Status of English Education" in FY 2015]. Retrieved February 22 $2^{\text {nd }}, 2017$, from http://www.mext.go.jp/a_menu/kokusai/gaikokugo/1369258.htm

Mori, S. (2001). Nichijyo sekai to ikigai no kankei [The relationship between everyday life and ikigai]. In Y. Takahashi \& S. Wada (Eds.). ikigai no shyakai-gaku: Kourei-shyakai ni okeru koufuku toha nanika [A sociology of ikigai: What is happiness in an aging society?] (pp. 91-110). Tokyo, Japan: Koubundou.

Mouer, R. E. (1997). Book review of What Makes Life Worth Living? How Japanese and Americans make sense of their worlds by Gordon Mathews. The Journal of Japanese Studies, 23(1), 210-214. doi: 10.2307/133144

Noddings, N. (1984). Caring: A feminine approach to ethics and moral education. Berkeley, CA: University of California Press.

Ohtani, C. (2010). Problems in the assistant language teacher system and English activity at Japanese public elementary schools. Educational Perspectives, 43(1-2), 38-45.

Onwuegbuzie, A. J., Dickinson, W. B., Leech, N. L., \& Zoran, A. G. (2009). A qualitative framework for collecting and analyzing data in focus group research. International Journal of Qualitative Methods, 3(8), 1-21.

People for education (2019). What makes a school? Annual report on Ontario's publicly funded schools. Toronto, ON: Author.

Solomon E. P, Berg L. R, Martin D. W. (2011). Biology. Belmont: Brooks/Cole.

Sone, T., Nakaya, N., Ohmori, K., Shimazu, T., Higashiguchi, M. et al. (2008). Sense of life worth living (ikigaı) and mortality in Japan: Ohsaki study. Psychosomatic Medicine, 7O(6), 709-715. doi: 10.1097/PSY.obo13e31817e7e64.

Stake, R. E. (1995). The art of case study research. Thousand Oaks, CA: Sage Publications.

Strauss, A. L., \& Corbin, J. M. (1998). Basics of qualitative research: Techniques and procedures for developing grounded theory. Thousand Oaks, CA: Sage Publications.

Tanno, K., Sakata, K., Ohsawa, M., Onoda, T., Itai, K., Yaegashi, Y., \& Tamakoshi, A. (2009). Associations of ikigai as a positive psychological factor with all-cause mortality 
and cause-specific mortality among middle-aged and elderly Japanese people: Findings from the Japan Collaborative Cohort Study. Journal of Psychosomatic Research, 67(1), 6775. doi: 10.1016/j.jpsychores.2008.10.018

Wada, S. (2006). Kourei-shyakai ni okeru “ikigai" no ronri [The logic of ikigai in an aging society]. ikigai Kenkyuu, 12, 30-35.

Yin, R. K. (2009) Case study research designs and methods (4th ed.). Thousand Oaks, CA: Sage Publications.

Zwart, R. C., Wubbels, T., Bergen, T.C.M., \& Bolhuis, S. (2007). Experienced teacher learning within the context of reciprocal peer coaching. Teachers and teaching: Theory and practice, 13(2), 165-187.

\section{About the Author}

Olenka Bilash is professor of second language education in the Department of Secondary Education, Faculty of Education, University of Alberta and North American representative to LINGUAPAX, a UNESCO-affiliated organization designed to advocate for all languages in the world and plurilingualism. Her research interests and practice focus on teacher professional development, study abroad, identity formation and transformation, global citizenship awareness education, qualitative research methodologies, marginalized communities, critical literacy and intercultural competency. Multilingual, she has served on teacher education projects on five continents. 